\title{
NONPRIMITIVE TRANSLATIONS FOR A FINITE LINEAR CHAIN
}

\author{
A. Wal, M. Kuźma \\ Institute of Physics Higher Pedagogical School, \\ Rejtana 16A, 35-310 Rzeszów, Poland
}

(Received July 16, 1998; received in final form April 5, 1999)

\begin{abstract}
According to the recipe of Weyl the full symmetry of a finite one-dimensional chain is described by the group which is the extension of the translation group by the group of its automorphisms. One can propose a method based on the embedding of one group in another which allows us to derive the nonprimitive translation for these extensions. The example of such calculations is given for the groups of the orders of 48 and 6.
\end{abstract}

Key words: linear crystals, symmetry, nonprimitive translation.

PACS numbers: 61.50.Ah

\section{INTRODUCTION}

The progress in the electronic material technology offers the possibility of designing and obtaining small size materials with a finite number of atoms placed in any preplanned way. One can see that finite crystals can have, compared with the infinite ones, new properties [1]. Hence, it appears that we should investigate such a system, especially the properties that result from its symmetry.

In this article a finite linear chain is considered with $N$ identical nodes placed in such a manner that the distance between them is the same. It forms a closed structure within the Born-Karman periodic boundary conditions. This model exhibits a symmetry, described by the cyclic group $C_{N}$, which is called a group of obvious symmetry. According to the Recipe of Weyl [2] essential features of such a system are related to another group, namely to the group Aut $C_{N}$ of all automorphisms of the group $C_{N}$ of obvious symmetry. The group Aut $C_{N}$ is called the hidden symmetry group of the system.

Let us introduce the notations:

$$
\tilde{N}=\{l \mid l=1,2, \ldots, N\}
$$

$\tilde{N}$ denotes the set of chain's nodes and

$$
C_{N}=\{j \mid j=1,2, \ldots, N\}
$$

is the cyclic group. The group of automorphisms is defined as follows:

$$
\operatorname{Aut} C_{N}=\left\{\tau_{i}^{N} \mid \operatorname{lcd}(N, i)=1\right\}
$$

where lcd means the great common divisor of $N$ and $i$. The number of elements of Aut $C_{N}$, is related to the value of $N$, but (except for the case when $N=2$ ) two automorphisms $\tau_{1}^{N}$ (identity automorphism) and $\tau_{N-1}^{N}$ can always be found.

The group that describes the full symmetry (obvious and hidden) of a structure is the extension $G$ of the group Aut $C_{N}$ by the group $C_{N}$. In this way the cyclic group plays the role of a translation group whereas the Aut $C_{N}$ is a point group. In the traditional three-dimensional crystallography the group $G$ can be characterised in two ways: by nonprimitive translations or by factor systems [3]. There is a transformation from one description to another through the formula which connects the factor systems and the nonprimitive translations. Unfortunately, this formula does not give a direct way to determine the nonprimitive translations for the one-dimensional case despite the fact that we know the factor systems. In this paper a method for calculating the nonprimitive translations for a finite one-dimensional chain is presented. This method is based on embedding the symmetry group of such a system in a group which has similar features but a greater order.

The nonprimitive translations for linear chains create a possibility of a complete crystallographic description (with geometrical interpretation of elements of group $G$ ) of quasi-one-dimensional crystal like: line polymers, organic metals and semiconductor and even hightemperature superconductors [4-7]. One should emphasise that the nonprimitive translations for linear groups which have "pure" geometrical interpretations, were determined by Bozovic [4]. In this paper the algebraic formalism for the calculation of all nonprimitive translations is presented.

\section{THE FACTOR SYSTEM AND NONPRIMITIVE TRANSLATIONS}

In crystallography the space group $G$ describes the full symmetry of a crystal:

$$
G=\left\{(t+v(q), q) \mid t \in T, q \in P, v\left(\mathrm{id}_{\mathrm{P}}\right)=\mathrm{id}_{T}\right\},
$$

where $T$ is the translation group and $P$ is the point group, $\mathrm{id}_{\mathrm{P}}, \mathrm{id}_{T}$ are the identity elements of the groups $P$ and $T, v$ is the nonprimitive translation $v: P \rightarrow R_{3}$ which means a translation that is a linear combination 
of base vectors with rational coefficients. The multiplication rule for this group is given by the expression

$$
\begin{aligned}
& (t+v(q), q)\left(t^{\prime}+v\left(q^{\prime}\right), q^{\prime}\right) \\
& =\left(t+q t^{\prime}+v(q)+q v\left(q^{\prime}\right), q q^{\prime}\right) .
\end{aligned}
$$

The group $G$ can be also considered as an extension of the group $P$ by the group $T$. The elements of the group $G$ are denoted as the pairs $(t, q), t \in T, q \in P$. The multiplication rule for this case is

$$
(t, q)\left(t^{\prime}, q^{\prime}\right)=\left(t+\Delta(q) t^{\prime}+\varphi\left(q, q^{\prime}\right), q q^{\prime}\right) .
$$

The extension defined in such a way is described by a factor system $\varphi: P \times P \rightarrow T$ and by the action $\Delta$ of the group $P$ on the group $T$. The extensions which differ only by the trivial factors $\varphi\left(q, q^{\prime}\right)=\mathrm{id}_{\mathrm{T}}$, where $\mathrm{id}_{T}$ is the identity translation, are equivalent [8]. There is a relation between the nonprimitive translations and the factor systems:

$$
v(q)+q v\left(q^{\prime}\right)-v\left(q q^{\prime}\right)=\varphi\left(q, q^{\prime}\right) .
$$

The mapping $\varphi$ should also satisfy the condition:

$$
\begin{gathered}
q \varphi\left(q^{\prime}, q^{\prime \prime}\right)+\varphi\left(q, q^{\prime} q^{\prime \prime}\right)=\varphi\left(q, q^{\prime}\right)+\varphi\left(q q^{\prime}, q^{\prime \prime}\right), \\
q, q^{\prime}, q^{\prime \prime} \in P
\end{gathered}
$$

which is the consequence of the associative law for the group $G$. For each pair $P$ and $T$ there are many extensions of the group $P$ by the group $T$, but the number of the nonequivalent extensions is much lower than the number of all extensions.

\section{SYMMETRY OF THE FINITE LINEAR CHAIN}

For the system under consideration the group $\operatorname{Aut} C_{N}$ plays the role of the point group whereas the cyclic group $C_{N}$ is the translation group. The group $G$, which describes both the hidden and the obvious symmetries of the chain, is defined as follows:

$$
G=C_{N} \square_{\Delta} \operatorname{Aut} C_{N}
$$

The action $\Delta$ is given by the formula

$$
\Delta: \operatorname{Aut}_{N} \rightarrow \operatorname{Aut} C_{N}
$$

The classification of the extensions can be done with the application of the cohomology group and Mac Lane's method [9-11] which is a very useful method for doing it. This method is based on the free group theory and makes it possible to determine the second cohomology group $H_{\Delta}^{2}(P, T)$ for all the possible actions $\Delta$. Each element of $H_{\Delta}^{2}(P, T)$ is associated with the factor system. A large number of extensions which are classified by the factor systems $\varphi\left(\tau^{N}, \tau^{N}\right), \tau^{N}, \tau^{N} \in$ Aut $C_{N}$ have been obtained by this method, even for a low value of $N$. For all these extensions Mac Lane's method allows to calculate the factor systems but does not determine the nonprimitive translations which are more interesting from the physical point of view because they offer an obvious crystallographic interpretation. In the next section we propose a method for determining such translations.

\section{THE NONPRIMITIVE TRANSLATION}

When considering a one-dimensional crystal the question about the nonprimitive translations is the question about the image of the mapping $v$. For finding these nonprimitive translations we use the embedding of one group in another. Let us consider the following mapping [12]

$$
f_{1}: C_{N} \rightarrow C_{M} \text { for } N \text { being the divisor of } M
$$

which maps the cyclic group $C_{N}$ into the cyclic group $C_{M}$ of a greater order $(M>N)$. An example of such a mapping for $M=12$ and $N=3$ is presented in the next section.

The next mapping $f_{2}:$ Aut $C_{N} \rightarrow$ Aut $C_{M}$ that describes the action of the group Aut $C_{N}$ on the group $C_{M}$ is introduced. It satisfies the equation

$$
f_{2}\left(\tau_{1}^{N}\right)=\tau_{1}^{M}
$$

where $\tau_{1}^{N}$ and $\tau_{1}^{M}$ are identity automorphisms in the group Aut $C_{N}$ and $\operatorname{Aut} C_{M}$, respectively. Now we can define the nonprimitive translations for the group $G=$ $\operatorname{Aut}_{N} \square_{\Delta} C_{N}$ :

$$
v: \operatorname{Aut} C_{N} \rightarrow C_{M}
$$

The image of the mapping $v$ is the set of translations which belong to the group $C_{M}$ but some of them, called nonprimitive translations, do not belong to the image $v \notin f_{1}\left(C_{N}\right)$. By summing up these nonprimitive translations we can obtain a translation that is primitive, which means that it belongs to the set $f_{1}\left(C_{N}\right)$.

The relation between the factor systems and the nonprimitive translations for the group $G$ can be written as follows:

$$
\begin{aligned}
f_{1}\left(\varphi\left(\tau^{N}, \tau^{N}\right)\right) & =v\left(\tau^{N}\right)+f_{2}\left(\tau^{N}\right) v\left(\tau^{N}\right) \\
& -v\left(\tau^{N} \tau^{N}\right)
\end{aligned}
$$

where $\tau^{N}, \tau^{N} \in \operatorname{Aut} C_{N}, v\left(\tau^{N}\right)$ is the nonprimitive translation for the group $G$ and $\varphi\left(\tau^{N}, \tau^{N}\right)$ are the factor systems. 
To determine the nonprimitive translations we choose the mappings $f_{1}$ and $f_{2}$ and then we solve the equation (14) for all the possible values of $\tau^{N}$ and $\tau^{N}$. The cases when $\tau^{N}=\tau^{N}=\mathrm{id}_{\mathrm{Aut} C_{N}}$ are trivial because the solution $v=\mathrm{id}_{C_{M}}$ is the primitive translation.

Let us solve equation (14) for two automorphisms $\tau^{N}, \tau^{N} \in\left\{\tau_{N-1}^{N}, \tau_{1}^{N}\right\}$. The action of automorphism on the group $C_{N}$ is defined as follows:

$$
\tau^{N} j=i j \bmod N
$$

Let $M$ be the divisor of $N$, then the natural mapping for $f_{1}$ is

$$
f_{1}: j \rightarrow j \frac{M}{N}=j^{\prime}, \text { for } j \in C_{N}, j^{\prime} \in C_{M}
$$

The mapping $f_{2}$ for the two previously chosen automorphisms can be written as:

$$
\begin{aligned}
f_{2}\left(\tau_{1}^{N}\right) & =\tau_{1}^{M} \\
f_{2}\left(\tau_{N-1}^{N}\right) & =\tau_{M-1}^{M}
\end{aligned}
$$

The solutions of the equation (14) for the cases when one automorphism is an identity automorphism are trivial:

$$
\begin{aligned}
& f_{1}\left(\varphi\left(\tau_{1}^{N}, \tau_{N-1}^{N}\right)\right)=v\left(\tau_{1}^{N}\right), \\
& f_{1}\left(\varphi\left(\tau_{N-1}^{N}, \tau_{1}^{N}\right)\right)=(M-1) v\left(\tau_{1}^{N}\right) .
\end{aligned}
$$

In both cases $v\left(\tau_{1}^{N}\right)$ is equal to the identity element $\mathrm{id}_{C_{M}}$ in the group $C_{M}$. A nontrivial equation (14) is obtained when $\tau^{N}=\tau^{N}=\tau_{N-1}^{N}$ :

$$
\begin{aligned}
f_{1}\left(\varphi\left(\tau_{N-1}^{N}, \tau_{N-1}^{N}\right)\right) & =v\left(\tau_{N-1}^{N}\right)+f_{2}\left(\tau_{N-1}^{N}\right) v\left(\tau_{N-1}^{N}\right) \\
& -v\left(\tau_{N-1}^{N} \tau_{N-1}^{N}\right) .
\end{aligned}
$$

The solution of (19) is

$$
f_{1}\left(\varphi\left(\tau_{N-1}^{N}, \tau_{N-1}^{N^{\prime}}\right)\right)=M v\left(\tau_{N-1}^{N}\right)-M
$$

Since the composition law for the group $C_{M}$ is defined as modulo $M$, the last element on the right side of equation (20) can be neglected. Therefore, the solutions are $v \in \tilde{M}=\{1,2, \ldots M\}$ and the nonprimitive translations are the elements $j \in \tilde{M}$ which do not belong to the image of $f_{1}\left(C_{N}\right)$.

\section{EXAMPLE $M=12, N=3$}

The group Aut $C_{12}$ has four elements $\left(\tau_{1}^{12}, \tau_{5}^{12}, \tau_{7}^{12}, \tau_{11}^{12}\right)$ whereas the group Aut $C_{3}=\left\{\tau_{1}^{3}, \tau_{2}^{3}\right\}$. The mapping $f_{1}$ is defined as:

$$
f_{1}: j \rightarrow j^{\prime}=4 j, \quad \text { where } j^{\prime} \in C_{12}, j \in C_{3}
$$

and the mapping $f_{2}$ as:

$$
\begin{aligned}
& f_{2}\left(\tau_{1}^{3}\right)=\tau_{1}^{12} \\
& f_{2}\left(\tau_{2}^{3}\right)=\tau_{11}^{12}
\end{aligned}
$$

Equation (19) for our example is:

$$
f_{1}\left(\varphi\left(\tau_{2}^{3} \tau_{2}^{3}\right)\right)=12 v\left(\tau_{2}^{3}\right)
$$

The translations that satisfy this equation are primitive and nonprimitive in the group $C_{3}$. These nonprimitive ones do not belong to the image of $f_{1}\left(C_{3}\right)$ and they form the set $\{1,2,3,5,6,7,9,10,11\}$. The corresponding factor system $\varphi\left(\tau^{3}, \tau^{\prime 3}\right)$ is trivial:

$$
\varphi\left(\tau^{3}, \tau^{3^{\prime}}\right)=3 \text { for all } \tau^{3} \in\left\{\tau_{1}^{3}, \tau_{2}^{3}\right\}
$$

\section{CONCLUSIONS AND REMARKS}

The method presented above creates a possibility of calculating the nonprimitive translations for the group $G$ which describes, according to the Recipe of Weyl, the full symmetry of a one-dimensional finite crystal. The knowledge of the full symmetry allows us to notice new properties of mesoscopic physical systems, which are now often studied and applied in microelectronics. As an example of a new property the Heisenberg magnet with finite and small number of nodes may be given. For this system the group of hidden symmetry determines the distribution of the quantum states in the Brillouine zone - the density of these states is constant for such quasimonenta, which form an orbit of the action of the group Aut $C_{N}$ on the set of elements of the Brillouine zone [13].

The idea of formalism used in the paper for calculating the nonprimitive translations consists in a group theory construction called embedding. The nonprimitive translations in the small (in the sense of group order) group $C_{N}$ are primitive translations in the large group $C_{M}$. The restriction for embedding is that $N$ should be a divisor of $M$. It has been shown that even for certain particular automorphisms a large set of nonprimitive translations may be found. 


\title{
A. WAL, M. KUŹMA
}

[1] M. Kuzma, in Symmetry and Structural Properties of Condensed Matter, edited by W. Florek, T. Lulek, M. Mucha (World Scientific, Singapore, 1991), p. 379.

[2] H. Weyl, Symmetry (Princeton U.P., New Jersey, 1952).

[3] J. Mozrzymas, Applications of Group Theory in Physics (Polish Sci. Publ. (PWN), Warsaw, 1976).

[4] M. Vujicic, I. B. Bozovic, F. Herburt, J. Phys. A 10 , 1271 (1977); I. B. Bozovic, M. Vujicic, J. Phys. A 11, 2133 (1978); I. B. Bozovic, M. Vujicic, J. Phys. A 14, 777 (1981).

[5] J. T. Devresse, Y. E. van Doren eds., Highly Conducting One-Dimensional Solids (Plenum-Press, 1979).

[6] G. A. Tombs, Phys. Rep. C 40, 181 (1978).
[7] D. Jerome, H. J. Schultz, Adv. Phys. 31, 4, 299 (1982).

[8] A. Wal, Rep. Math. Phys. 34, 113 (1994).

[9] S. Mac Lane, Ann. Math. 50, 736 (1949).

[10] T. Lulek, Acta Phys. Pol. A82, 377 (1992).

[11] T. Lulek, R. Chatterjee, Acta. Phys. Pol. A82, 395 (1992).

[12] W. Florek, D. Lipiński, T. Lulek, in Symmetry and Structural Properties of Condensed Matter, edited by W. Florek, D. Lipiński, T. Lulek (World Scientific, Singapore, 1993), p. 389.

[13] B. Lulek, Recipe of Weyl, nonregular orbits and translational symmetry breaking of one-dimensional Heisemberg magnet (Scintific Publication UAM, Poznań, 1993).

\section{НЕПРИМІТИВНІ ТРАНСЛ ЯЦІЇ ОБМЕЖЕНОГО Л ІНІЙНОГО Л АНЦЮЖКА}

\author{
А. Валь, М. Кузьма \\ Інститут фізики, Вища педагогічна икола, \\ Рейтана, 16А, Жешуб, 35-310, Польща
}

\begin{abstract}
Розглянуто симетрію скінченого одновимірного ланцюжка, який складається з $N$ тотожних рівновіддалених вузлів і задовольняє крайові умови Борна-Кармана. Згідно з процедурою Вайля, симетрію такого ланцюжка описує група, яка $є$ результатом операції розширення групи $C_{N}$ через групу автоморфізмів $\mathrm{Aut}_{N} .3$ кожним таким розширенням пов'язана система множників, яка визначає закон групового множення. Крім того, закон групового множення може бути заданий непримітивними трансляціями.

Завдяки теоретико-груповій конструкції, якою є вкладення одної групи в іншу, запропоновано метод визначення таких непримітивних трансляцій. Розглянуто вкладення групи Aut $C_{N} \square C_{N}$ у групу Aut $C_{M} \square C_{M}$ для $M>N$ кратного $N$. Застосований метод дозволив визначити непримітивні трансляції для вибраних автоморфізмів, які нале жать до $\mathrm{Aut}_{N}$. Конкретний розрахунок проведено для випадку $M=12, N=3$.
\end{abstract}

